\title{
Taking on new challenges: just fun for Paul Rothman
}

I n June 2008, Paul Rothman became dean of the University of Iowa Roy J. and Lucille A. Carver College of Medicine. He took up this position four years after moving from Columbia University College of Physicians and Surgeons in New York to the University of Iowa to be head and a professor of internal medicine at the Carver College of Medicine and University of Iowa Hospitals and Clinics. The JCI spoke with Rothman about his transition to the new position and how he is balancing his new responsibilities with those of a successful physician-scientist.

JCI: You were appointed dean of the Carver College of Medicine in June. How do you manage to balance the demands of this new position, running a highly successful research laboratory, and spending time in the clinic?

Rothman: I'm only in my fourth month in the position and so I'm still learning about the job and how to fit everything in. One of the biggest changes I made when I took the job, however, was to stop seeing patients; it wasn't fair to them. Other than that, I work hard - I spend my days seeing people and my nights reading and writing science - and I have a great lab full of talented people who enable me to spend a lot of time on my responsibilities as dean. But I love the job, it is a lot of fun and it is posing many new challenges for me.

JCI: What are you enjoying most about the new position?

Rothman: As we have an integrated medical school, research facility, and hospital, I get to mentor and work with so many exceptional people: medical students, new faculty, and department chairs. I get a lot of enjoyment out of mentoring people and watching them grow and succeed (getting their first grant, their publications, etc). The pleasure I get from facilitating the success of others is probably the main reason that I was enthusiastic about taking up this position and that I get so much satisfaction from it.
JCI: What are the biggest challenges you have faced so far?

Rothman: My first act as dean was to shut down the medical school for a week. It was when Iowa City was hit by severe flooding. Only one road into and out of the medical center was accessible, and we wanted to make sure this was open for emergency vehicles so we shut the medical school. We also lost the power plant and all our steam. We have now recovered from the effects of the flooding, but it was big challenge that I never expected to face.

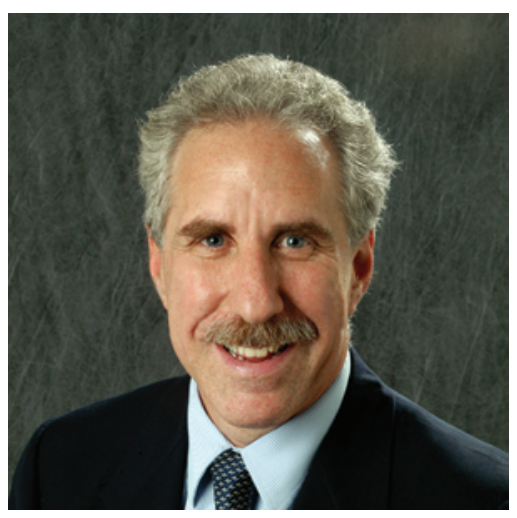

Paul Rothman is having fun and enjoying the challenge of being dean of the University of lowa Roy J. and Lucille A. Carver College of Medicine.

On a day-to-day basis, the challenges I face are similar to those faced at many other institutions. There are a lot of issues currently facing academic medicine, and the challenge is to balance the time and effort needed to work out ways to address these with the time needed to ensure the normal running of the medical school, research facility, and hospital (I run the practice plan) as well as planning ahead.

JCI: You have only been in the position for four months, but do you have any big plans that you are hoping to achieve while you are dean?
Rothman: There are two big projects that I'm working on right now. First, we are planning a brand new interdisciplinary research building. There will be an imaging floor and space for bioinformatics as well as more traditional biomedical research. It is a university-wide project but the building will be on the medical site and I have a role in the planning and fund-raising efforts. Second, the University of Iowa was awarded a Clinical and Translational Science Award (CTSA) last year and I am involved in how we should move forward with this. Research in the postgenomics era is rapidly evolving and has become interdisciplinary. How to incorporate this genetic and genome component into patient care is one of the biggest challenges that we are facing in academic medicine.

JCI: Speaking of challenges, you moved to Iowa City from New York in 2004, is there anything you miss about living and working in NYC?

Rothman: Chinese food. Also, there aren't as many restaurants to choose from, although there are enough for me, and I love it here. Life is easier here, and the people in the state of Iowa take a lot of pride in their hospital and College of Medicine.

JCI: What response have you got from people in Iowa to your strong New York accent?

Rothman: What accent?

JCI: Having spent many years as a successful physician-scientist what advice do you have for those just beginning their careers?

Rothman: Do what you love. If you love research, do it, don't worry about NIH budgets. Work hard, focus on what you love, and it will work out. Being a physician-scientist is the best career; I can't believe that I'm paid to do something I care passionately about - helping to cure people.

\section{Karen Honey}

